\title{
Challenges for the psychologist in gametes and embryo donation: A Brazilian perspective
}

\author{
Quayle $\mathrm{J}^{\mathbf{I}^{*}}$ and Detílio $\mathrm{AR}^{2}$ \\ ${ }^{1}$ Department of Preventive Medicine, Faculdade de Medicina, University of São Paulo, Av Dr Arnaldo 455, São Paulo, Brazil \\ ${ }^{2}$ Clin PsycholCentro de Reprodução Humana Assistida Fertivitro-SP, Brazil
}

"Human fertility is highly sensitive to emotional movements. Unconscious representations infiltrate the child project, can make it fail, and sometimes come into conflict with the wish of a child, as conscioulsly declared [1]."

\section{Donation of genetic material and new family configurations}

Medicine has chosen procreation as a new therapeutic goal. This would have been previously unthinkable and not doable [2]. Recent contributions in several areas of the health sciences have made possible countless forms of addressing infertility issues. Preservation of reproductive genetic material favored parenthood for countless individuals previously confronted with biological or social infertility, opening new treatment perspectives and provoking important reflections about family organization. The evolution of reproductive medicine has been collaborating with the emergence and consolidation of new family organizations and contexts. Furthermore, new ethical dilemmas have appeared, showing the need of exploring emerging complexities in the area of assisted reproduction. At this point it is essential to promote the revision of rooted concepts and paradigms related to the traditional family constitution, particularly considering the possibilities offered by these new reproductive technologies.

Corrêa and Loyola [3] maintain that Assisted Reproduction (AR) reinforces sociologically important standards. They emphasize that "it is the child who makes the family". The very concept of "involuntary absence of children" in the context of AR brings up a new paradigm: the use of AR techniques (ARTs) goes beyond the treatment of biological infertility and is expanded to include any and all problems and gaps in the management of individuals' reproductive plans. More than that: it looks for the alignment of reality to dreams, of reproductive wishes of individuals and couples, incorporating the rectification and also the "correction" of faults in the procreating plans of people"

From a humanist and interdisciplinary perspective, psychology has studied the subject aiming at understanding related issues and collaborating with AR medicine, to harbor patients' and professionals' demands. These are mainly provoked by new, complex, conflicting and unknown experiences. Most demands relate to the psychological and emotional repercussions of these practices. The ethical, moral, anthropological, economic and social challenges associated with the use of donated genetic material must also addressed and, in doing so, it is necessary to consider each individual, each couple and each family, since each brings different demands regarding the constitution of the family in the context of assisted human reproduction.

As stated by Bydlowski [1], fertility is extremely sensitive to emotional movements and unconscious representations that permeate the parental project. First, the use of AR implies the acceptance of a third, "an other" in the couple's relation. Here we refer specifically to the doctor and the interdisciplinary team, including the psychologist. This issue and its consequences have been widely discussed by AR experts. This intrusion may provoke deadlocks, control and paranoid anxiety to the couple and hinder their sexual life in a moment they feel under scrutiny. This may constitute an important challenge to the parental project itself, even in situations where the couple's own genetic material is employed. It can only be imagined, then, that the introduction of one more character in the equation - the donor(s) - could bring new and important interferences, imbalancing the couple's psychological adaptation mechanisms efforts.

Therefore, our objective is to examine the heterologous donation/ reception of genetic material to understand the demands posed to both hetero and homoafective couples. We hope these considerations will help to strengthen an appropriate approach, an awareness of patients' needs and a healthy sharing of information. Last, but no less important, we aim at increasing the perception of new family arrangements and new types of relationships resulting from the use of TRA, enlarging the conception of healthy and socially acceptable family organization and definitions.

\section{Brazilian norms}

Due to the ethical, social and emotional implications of the procedures, institutions and organizations related to its practice have proposed guidelines and recommendations. Specific orientations are available as to indications, feasibility, evaluation of those involved and accepted techniques [4]. It is Important to point out that consultation with the psychologist is included as part of the proposed protocol. This and other similar propositions show recognition of the work of this professional in the evaluation and assistance of infertile patients.

Donation and reception of genetic material is becoming more and more common in Brazil. The Federal Council of Medicine (Conselho Federal de Medicina, CFM, Institution that regulates the medical profession in the country), contemplates these procedures with regular updates. In the 2017 [5] version, it regulates the use of genetic material in assisted reproduction and prohibits, for instance, that members of the

${ }^{*}$ Correspondence to: Julieta Quayle, $\mathrm{PhD}$, Clin Psychol, Department of Preventive Medicine, Faculdade de Medicina, University of São Paulo, Av Dr Arnaldo 455, São Paulo, Brazil, E-mail: jquayle@uol.com.br

Received: October 15, 2018; Accepted: October 22, 2018; Published: October 29,2018 
multiprofessional team become donors or receivers of genetic material to/from patients of the clinic where they work. CFM emphasizes that this donation must not have a profitable or commercial character and that the identity of donors and receivers should be protected. It also establishes age limits for feminine and masculine donation (35 and 50 years old respectively). Regarding the donation of cryopreserved embryos, patients must declare in writing their will with respect to the destiny of surplus embryos, as well as what should be done if one of the members of the couple dies or if the relationship ends. Three years has been established as the legal limit to carry out the disposal of excess abandoned cryopreserved embryos.

This resolution authorizes the voluntary and unilateral donation of female gametes, making it possible for any woman to go to a clinic and donate her eggs, which was not allowed before. It also considers the sharing of eggs in situations where donor and receptor have infertile problems and are participating in the same program. This enables the sharing of genetic material and financial costs, involved in the AR procedure. It is considered, however, that the donor will have a preference on the genetic material, since the agreement is signed before they know how many eggs the donor will have. The donation of female gametes in Brazil is most common among patients undergoing infertility treatment; a spontaneous donation is rare.

The donation of masculine gametes is associated with more consolidated practices and techniques, with larger acceptance, mainly due to the relatively simple collection and use of the material. However, in the current Brazilian scene, both homoaffective and heterosexual couples have been opting for importation of genetic material, mainly from the United States. Some of the reasons for this includes the larger number of available donors and bank, as well as the amount of information about the donors and the quality of the material. Availability of information on personality traits, phenotypes and donor health are a plus to be considered. The access to a childhood or adolescent photo of the donor could be an irresistible temptation for those who want to have their descent presenting similar physical traits and can pay for that luxury. In Brazil, the number of masculine gamete banks is comparatively inferior and the price difference, in comparison to imported material, is not very high.

As a patient said: "I prefer to bring it from abroad and guarantee the origin and quality of the sperm who will be the father of our son" (GT, 35 years old, female homoaffective couple).

\section{The daily challenges in the clinic}

The use of female genetic material is more recent and implies more complex and invasive procedures and frequently implies its use by the patient herself. The feminine donation of gametes is associated with, and results from, intense breaks in the models of family organization.

Some studies [6,7] suggest that one of women's motivations for donation in Brazil is the common experience of infertility and the donor's will to help since she acknowledges the psychological pain of not having her own child. They also show that it is easier do donate than to receive genetic material, and that religious questions often limit the participation in programs of shared donation. One study [6] investigated the association between sociodemographic variables and the disposition to donate / receive ova among 319 women. The majority $(56,9 \%)$ responded they would donate eggs; only $34,5 \%$ would accept to receive. Women with higher and low levels of schooling were more open to donation $(55,4 \%$ and $61,3 \%$, respectively, but against the idea of being a receiver $(37,5 \%$ and $33,9 \%$, idem). Women who had already been under infertility treatments were more favorable to donate $(63,4 \%$ yes vs $36,6 \%$ no) when compared to those without previous treatment, but not to receive it (41,8 \% yes vs $58,2 \%$ not). In short, it seems to be more difficult to receive than to donate gametes and this appears to be associated with two questions: the self-image of the donor- who can feel altruistic, and the difficult acceptance of heterologous genetic materialan aspect which has already been analyzed in adoption, acting as an important hamper.

Straeh et al. [7] carried out a cross-sectional study in Ribeirão Preto with 69 patients in treatment for infertility (with an average age of 34,5 years, from 23 to 44 years) They were evaluated during the induction of ovulation. Fifty-three per cent said they would not accept the donation of gametes because the child so conceived would not be their biological son and, in this case, they preferred to adopt. Four patients had never heard about this type of donation and $32(46,4 \%)$ were not willing to donate their own eggs. Among the rest, 21 (65.6\%) said they did not want "other women to have their biological children"; 8 (28.12\%) said they did not know enough about the technique and its implications to answer, and 3 (6.25\%) did not approve of it for religious reasons. The analysis showed that marital status, religion, schooling, occupation, type of infertility, age, duration of infertility, number of previous cycles of $A R$, average number of oocytes retrieved and average number of embryos per cycle had no influence on the acceptance of the donation or of the reception of oocytes. An interesting aspect raised by the authors, was that more than $90 \%$ of them believed that the question of "adoption" should be discussed during treatment, but they preferred to discuss this subject with psychologists and not with doctors.

One factor associated to the increase of donation is the current possibility of sharing treatment expenses; this minimizes costs of both receivers and donors and allows for more attempts. Receivers are aware that in cases of smaller amounts of eggs, the donor will have preference and the potential receiver might end up suffering emotionally and financially. These new proposals favor a new "paradigm", forging a model of reciprocity based on the adjustment of mutual needs, is considered by some more ethical and desirable than the simple purchase of genetic material- which, in Brazil, is not allowed anyway.

It is apparent, though, that there is a "free market" in the Internet, where offer/sale of genetic material is frequent. Brazilian women are seen offering their genetic material. We take the liberty to mimetize the authors and include here a figure from the internet showing the importance of discussing this subject (Figure 1).

Another fundamental issue refers to the fact that "the legitimacy of kinship relations manufactured by reproductive technologies presupposes the proximity with the genetic origin relations; " the lack of similarity between the child conceived through a donation of genetic material and his parents may reveal the secret of the donation, carrying the risk of being considered an illegitimate affiliation [8,9]". As a 46 year old patient said : "What makes me insecure as to adopt an embryo is not knowing what the child will be like, although we do think that the right way of doing things is to tell the truth... but it is difficult to think about this now." (R.S. 46 years). This shows ambivalence towards the decision of "telling the truth" and also the fear of having a child whose sole existence could spell out the secret.

A new perspective relates to the acquisition of genetic material by importing from certain European banks, where this market is legalized and recognized by the organizations which regulate the practice, both in Europe and in Brazil. What seems to make many couples choose this route, in spite of the high cost, is again the amount of information 
https://www.surrogatefinder.com/findeggdonors/

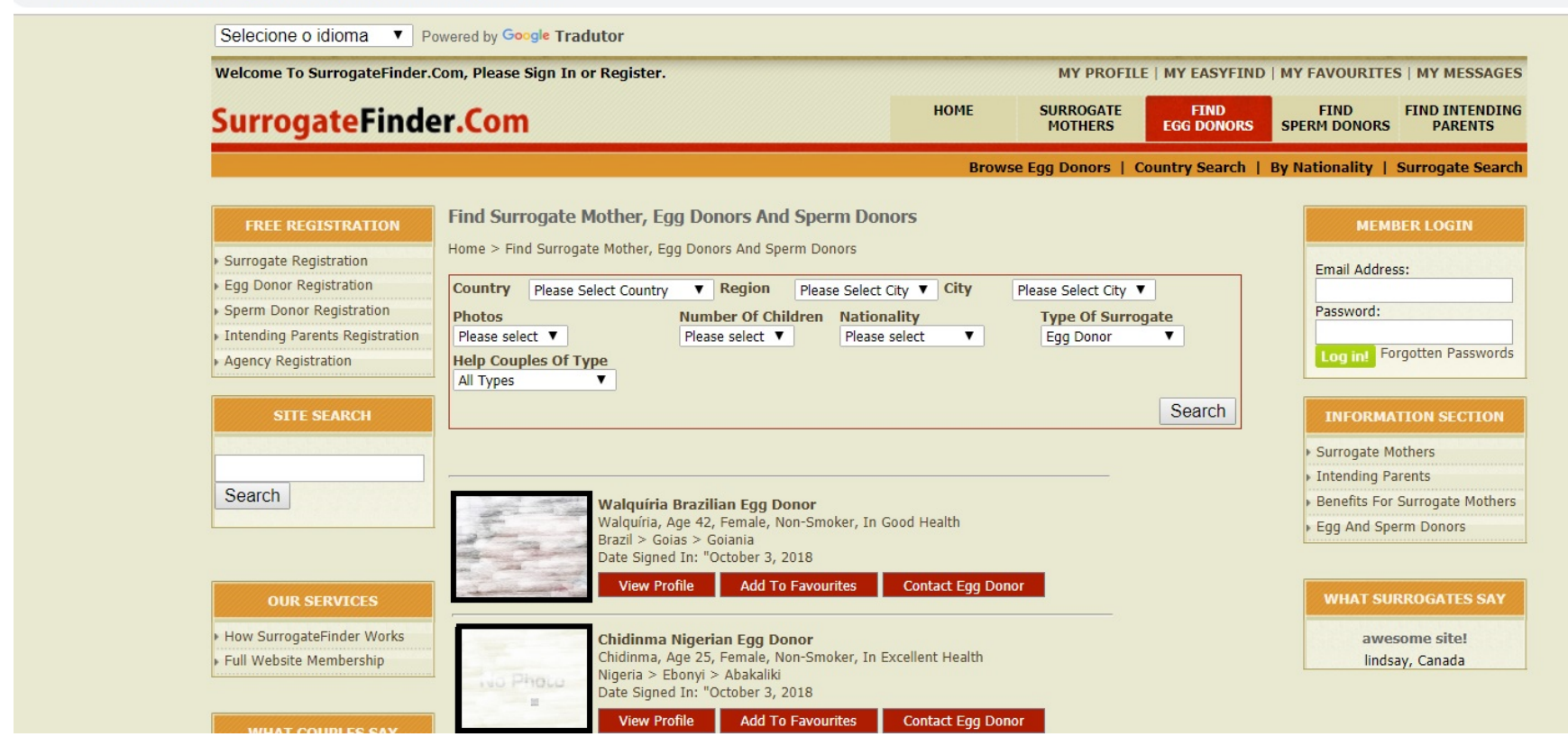

Figure 1. Example of an offer of genetic material in the internet (source: www.surrogatefinder.com, on September 29, 2018)

about the donor, the European stereotype (white, beautiful) and mainly the age of donors, which revolves around 19 to 27 years. The almost immediate availability of the gamete, so different from Brazilian reality, surely influences this decision. CD, 45 years old, simply says: "In spite of having been startled with how fast the ovum should arrive, and after having thought it through, I am tending towards bringing it from abroad (...) the donors are young, healthy and I am going to be able to have the treatment sooner". Quite a different reality from shared infertility treatments - where the donor is also in an infertility program due to her own infertility problems, being frequently older, and with no projected deadline.

A 40-year-old embryologist in a private clinic mentions the importance of matching physical characteristics, "even those that are not always visually identifiable: blood type, including the serology characteristics of the patient, everything... To match the cycle, the phenotype, the color of eyes and the hair, blood type (...) Because, you know, the patient has an option, she may not want to tell the child her/ his origin. After she becomes pregnant, she may not want to tell who the donor is, that there is a donor, who is the mother, and things like that." The very fact that a professional mention here "who is the mother" unveils how sensitive is this whole subject.

Phenotypic similarity symbolically substitutes the transmission of genes [10]. Attributing medical justifications to the immunological similarity criteria, in contrast with the 'phenotypic' similarity would aim at avoiding family problems regarding the non-mixture of races. The professional justifications demonstrate that the search for immunological similarity is also used to avoid betraying the secret of the donation to the children.

In this context a strong emotional component can emerge and justify the occultation of the truth: the need of using gametes from a donor. To legitimize the feeling of impotence for not conceiving like most people, "generating" and giving birth to a baby with characteristics similar to her own may feed the fantasy of being fertile, thus hiding the history of infertility and its treatment.

\section{Donation and reception: some emotional aspects}

"Don't misunderstand me. I am very grateful that everything went right and that I have my children with me today, healthy and pretty. So very mine ...but I can't stop thinking about what may have taken place with my children who resulted from the "eggs" I donated. I do not know if they are well, do not know if they are alive, do not know if they are happy. As a matter of fact, I do not even know if they were even born. Sometimes I am afraid of being punished and that something will happen because of having done this, but I prefer to believe that it was an act of love and that God will understand this and look after all my children" (MSF, 39 years old).

According to Bydlowski [1] fertility is extremely sensitive to emotions; unconscious representations permeate the parental project and affect its course. Beyond eventually questioning altruistic motives, the donation/reception of genetic material introduces a new character to the triangle already formed in the couple's imagination, thickening the plot. This new actor - the donor, in a certain way is backstage, in fact - and for quite a while - occupies a main role in the fantasies of gamete receivers. May steal the scene. As a matter of fact, this situation where a couple believes in the possibility of building a family with children genetically unrelated to their ancestors (or related to only one of them), sometimes is very difficult to elaborate and may feed fantasies of betrayal or abandonment [11].

Some of these procedures are emotionally conflicting, involving feelings of loss and grief for both donors and receivers, especially in situations of shared eggs $[12,13]$. Everybody has something to lose and something to gain, but losses sometimes feel huge, particularly because there is no assurance of the end results. All this puts relationship under scrutiny and reshapes parenthood and its meaning. The fact that sometimes the obtained embryo carries genetic material of only one of the couple's members can bring up rivalries, as well as feelings of incompetence and inadequacy in the other, building up a net of symptoms and psychosomatic demonstrations that may be difficult to be identified, diagnosed and appropriately treated. 
Giving up generating children with your own genetic material requires renouncement and surrender. It may mean resignation to reality more than going after dreams and wishes, "no matter what". It may bring forth many uncertainties, doubts and fears. Besides, the possibilities of success/failure at every step of the process are extremely stressful factors and potentially disruptive, especially in more vulnerable individuals or in couples who seek parenthood to maintain their bond or to solve other existing problems. Secrecy, silence and hiding, attitudes and behaviors towards family members and society, regarding the infertility treatment and its nature, usually adds weight on the shoulders of these emotionally and physically overloaded "Atlases".

Usually couples accept the idea of receiving genetic material after some frustrated attempts with their own gametes. As the possibilities of conceiving decrease they tend to be more open to different approaches. The "adoption" of another woman's egg still harbors a possible conception and some couples hold to the "epigenetic" idea (sic) that gestation might influence the transmission of some traits to the offspring. A 45-year-old woman carried out 6 IVF with her own eggs without success. The health team indicated the egg donation program. She did not return to the clinic for one year. On her return she said she has thought a lot about the proposed treatment during this year; that she realized that this possible son was not the son of her dreams but the son who she could have and despite not being genetically hers, this son would hers to carry out. She believed her pregnancy would bring her near to him, since she would be going to give him life. She mentioned that when she received the news before she did not accept the idea but now she was ready because she wanted to be a mother above all.

From the perspective of homoaffective couples, in addition to these challenges it is necessary to add all those inherent to the constitution and maintenance of their bond in a society that only recently started to gradually accept these new family organizations and that, very often, finds it difficult to accept their right to be parents.

As a matter of fact, the new reproductive techniques have contributed to significant changes in procreation, family constitution and parenthood. Socio-affective parenthood is a reality and in many cases consanguinity and bloodlines are not an issue any more. Many couples could already bring children from previous marriages, or adopt, without the use of ART. However, the possibility of using ARTs brings new socio and psychological challenges. No other reflects this more than the use of ARTs to help homoaffective couples.

The possibility of constituting using this treatment model influences the imagination: it is often mentioned that this "brings them closer" (PS, 36), and more similar to the dream of conceiving "like the others" and, therefore, approaching a more "conventional" form of procreating. Vitule et al. [14] suggest that the possibility of choosing the gametes that will constitute "the son", legitimizes the wish of being "in control of the factors" (in a situation with so little real control), "and materialize social and cultural meanings related to the concept of family, phenotypic and racial classifications and genetic history of donors." A significant factor in this context is the fact that the truth about conception will appear more obvious and this factor may lead the parents to decide when and how they will tell the truth to their son. An homoaffective feminine couple, after questioned on this subject, that they believed they would have to tell the truth about the male donor pretty soon due to the fact they are two women. They were not sure as to how and when they would do that, nor how they would be feeling then, but strongly felt that telling the truth would be the best way out. They believed their child would understand that what made them chose this path was love.
A qualitative Belgian [15] study with 10 homoaffective feminine couples investigated family communication referring to the disclosure of conception facts to the child. It pointed out that those couples who invested in creating family and affective connections with their children more than spending energy on this issue. Frequently the strategy employed to deal with the masculine participation in conception was to answer the children's questions - which, in turn, were influenced by social questioning about their family organization. The answers were offered according to what the mothers thought was the best way for the child to understand, which resulted in several different forms of answering the questions, depending on circumstances and children's age, helping to mold family communication when dealing with questions related to family identity.

These are some of the issues that permeate the treatment and the gestation linked to gamete donation. Besides all the relevant issues which are present in any infertility treatment, such as fear of failure, interference with sexual life, possibility of pregnancy loss, financial costs, couples undergoing ARTs with heterologous genetic material must face other challenges that test their commitment even further. They must elaborate the fact that this dreamed "biological child" is not completely so and deal with all the concurrent potential and related problems - where secrecy and silence is just one among many.

One should not expect unconditional acceptance from the couple's [13] - the perspective of having a child in your arms does not do away with, nor exclude, how everything began. The first step is to give up the expectation of a genetic child, with everything that this means and, in sequence, the acceptance of a situation where the doubts and uncertainties are much bigger than those which already exist in any conception and gestation.

Family constitution does not depend upon the methods nor the conditions of conception. Not even on the biological bonds per se. What builds a healthy environment for a satisfactory and appropriate emotional development and relations is the offer of sufficiently adapted parental functions. In other words, the quality of the parental bond and the affectionate investments offered to the new member of the family.

This context shows the importance of a mental health professionalthe psychologist, in the health team, as proposed by the American Society for Reproductive Medicine and Society for Assisted Reproductive Technology (ASRM \& SART) and by the Brazilian Association of Assisted Reproduction [Sociedade Brasileira de Reprodução Assistida (SBRA)].

\section{Psychological support}

Psychological assistance should be available for individuals and couples undergoing infertility treatment using ARTs, particularly those involving heterologous genetic material reception and or donation.Not just as an "extra", a "plus", but as a part of the treatment.

Psychological work in this context serves many purposes, from evaluation and screening to hosting ambivalent feelings, harboring aggressive feelings, grief and doubts, to dealing with fear and fantasies. It helps uncover the wishes and expectancies and to deal with the stressful situations that are present so often in infertility treatments. Moreover, it offers a non-judgmental locus where individuals and couples, donors and receptors, can listen to themselves and get in contact with their fears and griefs, hopes and expectancies. Where they can not only celebrate success but also face failures, anguish and grief in a friendly and professional environment. 
The same way a couple goes under clinical evaluation, a psychological evaluation should also be performed - not necessarily for a negative indication, but to assess couples strong and weak points and conflicts, to propose a customized intervention. The use of a reference evaluation protocol is advisable, as long as it is flexible and can be adapted to the situation specific needs. It is important to emphasize that the female donor's evaluation is also necessary, not only in shared programs but also when family or friend's genetic material is used.

Several factors can have an unfavorable influence in the donation process, such as:

a) the level of emotional support, which varies depending on age, bonding characteristics, social environment and emotional relations

- Usually people with weaker social support nets or superficial relationships will face more difficulties and will need more support, independently of the reason that created the situation (e.g., the couple may not have family or friends in the city because they recently moved in or because they are shy and resent being around others)

b) the level of emotional maturity

- More mature individuals tend to adapt better to unknown situations and have the tools to deal with new challenges, to postpone gratification and to elaborate grief and failures, being more resilient and facing tasks more objectively.

c) the level of previous stress not necessarily related to the infertility problems - including professional context and requirements and potential interference with the treatment

- When individuals and/or couples are already under high levels of stress before infertility treatments, and have not found efficient ways of coping, the treatment itself may constitute an important disruptive and unbearable crisis

d) the level and type of the couple's conflicts, including towards the treatment

- Sometimes the search for a gestation can be the top of an iceberg in a very conflicted relationship, or it may be that having a child is not necessarily the plan or wish of both involved. These conflicts towards treatment may be expressed in different ways, sometimes very subtle - like forgetting an appointment or taking a prescribed medication. Veiled aggression towards the medical doctor or the health team may also suggest a displacement of such feelings and tendencies.

e) the level of perceived family and social pressure

- It is not unusual that perceived social pressure to accomplish the parental plan "forces" couples to go beyond their own parameters and rules in order to "fit", engaging in procedures that they do not really want or trust. Or the opposite: the perception of family rejection of new technologies may lead to serious conflicts in the treatment, provoking psychosomatic symptoms and exacerbated reactions.

f) the level of information and its understanding

- It is fundamental that the health team be sure that all important information about procedures and potential results were delivered -including potential side effects and success rates. This is a part of ethical procedure and guidelines in health, being certain that patients received and understood delivered information will help carry out the treatment with less problems g) the decision of using a known or unknown donor

- Some people feel safer choosing a known donor, believing they have more control of the origin of the gametes and of the social and medical history of the donors. On the other hand, this may imply some unwanted proximity in the future, particularly if the donor is a relative [12].

\section{Recommendations}

The following recommendations are part of a paper published in 2018 in Brazil with a group of psychologists who work in Assisted Reproduction, under the referral of assisted reproductive associations $[16,17]$.

Psychologist's work, in the context of assisted reproduction, particularly using heterologous genetic material, requires this professional to have had a differentiated post grad formation and interdisciplinary knowledge. $\mathrm{He} /$ she has to acknowledge, understand and help enforce ethical guidelines and must be familiar with legal orientation, as well as with the stages of treatment and potential evolution and outcomes.

An integrated and integrative working relationship with the health team is fundamental while aiming at a humanized praxis. The psychologist must be able to select and share essential information with the team to optimize chances of treatment without betraying patients' trust and ethical borders.

Treatment guidelines must be precise and customized. The evaluation and treatment goals should be shared with patients, with all respect to their individuality. This should favor a congruent, scientific and ethical work. In the evaluation period, with or without the use of psychological tests (as the situation requires),cognitive, emotional, family and social aspects of the patients and couples should be performed to establish their conditions of coping with the challenges to come, considering their fears, expectations, defenses, vulnerability and flexibility, This diagnostic impression makes a prognosis proposal possible and helps to design the therapeutic plan.

The screening for more vulnerable individuals is part of everyday work in this context to avoid more serious problems in the treatment evolution- medically and psychologically. Sometimes focal and brief therapy are recommended. Besides, psychologists must be familiar with grief interventions and should be able to offer support to patients, family and, sometimes, the health team. It is never enough to emphasize the importance of feedback - both to patients and professionals. In more complex situations - such as surrogate pregnancy- potential donors and surrogate mother should also be included in the treatment proposal.

It Is fundamental to discuss with the donors of genetic material / cryopreserved embryos the destiny wanted for excess embryos. The psychology professional can and must be a facilitator of the decisionmaking process of these couples.

\section{Final considerations}

One important but not solved issue relates to the role of the State in the context of the involuntary absence of children [3]. The State "is not released of the responsibility of looking for solutions to questions caused by the use and access to new technologies" (in this case, AR). In fact, this is what the constitution predicts, within the 1996 law of family planning. It should give coverage not only to contraception, but also to conception." It goes further : "The allocation of budgetary resources in the area of health might create, obviously, obstacles as to eligibility 
(who has the right or "more right " to have this access), but this does not justify that the State should not provide solutions in this area, considering the conception of health also as a basic individual right in Brazil [3]. In a country so full of regional differences, this issue must eventually be included in the discussion of public policies.

The donation of genetic material these last years has become an important alternative for the treatment of infertile couples, particularly in situations of social infertility, which brings up a whole new group of questions associated to the concept of parenthood and its viability. In fact, it is becoming increasingly more evident that affiliation is above all else linked to a symbolic construction to orientate new family configurations [12].

When one starts AR treatments, an undeclared battle against time starts. The time to wait for a test result. The wait for the donor. The time to wait for a child. The time going by. The time to wait for (another) pregnancy test. The time when other attempts should stop. These are very present questions for couples who take this route. A battle not always recognized and valued.

"The future is hope. Is fear. Is ungraspable, untouchable. We live it many times in the present while planning the future [17]."

\section{References}

1. Bydlowski S (2014) The pains of medically assisted procreation: what place for psychic suffering?. Gynecol Obstet Fertil 42: 861-864. [Crossref]

2. Mathieu S (2013) Faire famille aujourd'hui: an ethics of l'Assistance médicale à laprocréation. Gynécologie Obstétrique \& Fertilité 41: 532-536

3. Corrêa MCD, Loyola MA (2015) Assisted Reproductive Technologies in Brazil: options for expanding access. Physis: Revista de Saúde Coletiva 25.

4. American Society for Reproductive Medicine and Society for Assisted Reproductive Technology (ASRM \& SART). Recommendations for gamete and embryo donation: committee opinion. Birmingham, Alabama. Fertility and Sterility, 99 (1) http://dx.doi. org/10.1016/j.fertnstert.2012.09.037
5. Federal Council of Medicine (CFM) Resolution 2168 / 2017.Brasília, CFM, 2017). Available at https://flaviotartuce.jusbrasil.com.br/noticias/519764480/resolucao-2168 2017-do-conselho-federal- of medicine

6. Parames, SF, Francisco LS, Almada-Colucci JD, Sato H, Ueno J (2014) What influences donation of eggs when there is no financial compensation? Reprod. Clim 29: 8-12

7. Straeh, J, Lara LAS, de Sa MSF, Reis RM, Rosa-e-Silva ACJS (2017) What do Infertile Women Think about Oocyte Reception, Oocyte Donation, and Child Adoption? Rev Bras Ginecol Obstet 39: 282-287. [Crossref]

8. Luna N (2005) Human nature created in the laboratory: biologization and genetization of kinship in the new reproductive technologies. History, Sciences, Health-Manguinhos 12: 395-417.

9. Luna $\mathrm{N}$ Provetas and clones: an anthropology of new reproductive technologies. Rio de Janeiro: Ed FioCruz, 2007.

10. Reproductive technologies and notions about racialization and ethnicity. In: Annual Meeting of ANPOCS XXVII, 2003, Caxambu.

11. Almeida CP, Seibel D, Makuch MY, Maluf V Guide on Mental Health in Human Reproduction Update - 2006. SBRH Psychology Committee 2005-2006 http://www. saudedireta.com.br/docsupload/1340367925guideline de psicologia.pdf

12. Farinati D, Montagnini H, Lopes HP(2012) Gametes Donation and its repercussions: the question of secrecy and emotional bonds. In the First Consensus of Psychology. Guarujá 2012. Brazilian Society of Assisted Reproduction. São Paulo: Free Expression, 2012

13. Maheseldt PP, Greenfeld DA (1989) Assisted reproductive technology with donor gametes: the need for patient preparation. Fertil Steril 52: 908-914. [Crossref]

14. Vitule C, Couto MT, Machin R (2015) Same-sex couples and parenting: a look at the use of reproductive technologies. Interface, 201519 (55). Available from http://www. scielo.br/scielo.php?script=sci_arttext\&pid=S1414-32832015000401169

15. Parys VH, Verkens WE, Provoost V, Sutter P, Pennings G, et al. (2016) Family communication about donor conception: a qualitative study with lesbian parents. Fam Process 55: 55-154. [Crossref]

16. Quayle J, Detílio, AR (2018) Donation and reception of genetic material I: heterosexual couples, homosexual couples. In: Straube, K Melamed, RMM Assisted Reproduction: A guide to psychosocial care recommendations in assisted reproduction centers. São Paulo: Editora Soul / SBRA (Brazilian Society of Assisted Reproduction, 2018.

17. Travain, A, Lourenço e Tardin, R: Time and assisted human reproduction. In Melamed, RMM Straube, KM Contemporary themes of psychology in assisted human reproduction: Infertility In Its Psychoemotional Spectrum. São Paulo: Livrus, 2015

Copyright: (C2018 Quayle J. This is an open-access article distributed under the terms of the Creative Commons Attribution License, which permits unrestricted use, distribution, and reproduction in any medium, provided the original author and source are credited. 